\title{
Patterns of renal injury in NIDDM patients with microalbuminuria
}

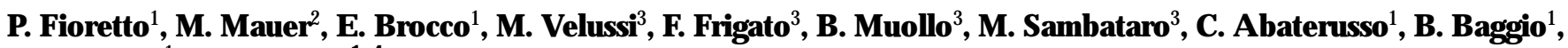 \\ G. Crepaldi ${ }^{1}$, R . N osadini ${ }^{1,4}$ \\ ${ }^{1} \mathrm{D}$ epartment of Internal M edicine and Center for the Study of A ging of the National R esearch Council, \\ U niversity of Padova Medical School, Padova, Italy \\ 2 Pediatric N ephrology, U niversity of M innesota M edical School, M inneapolis, M innesota, U SA \\ ${ }^{3} \mathrm{D}$ iabetes $\mathrm{C}$ enters of $\mathrm{M}$ onfalcone, $\mathrm{M}$ estre, $\mathrm{E}$ ste and Contarina, I taly \\ ${ }^{4} \mathrm{D}$ ivision of Endocrinology, U niversity of Sassari M edical School, Sassari, I taly
}

Summary Microalbuminuria predicts overt nephropathy in non-insulin-dependent diabetic (NIDDM) patients; however, the structural basis for this functional abnormality is unknown. In this study we evaluated renal structure and function in a cohort of 34 unselected microalbuminuric NIDDM patients ( 26 male/ 8 female, age: $58 \pm 7$ years, known diabetes duration: $11 \pm 6$ years, $\mathrm{HbA}_{1 \mathrm{c}}: 8.5 \pm 1.6 \%$ ). Systemic hypertension was present in all but 3. G lomerular filtration rate (GFR) was $101 \pm 27 \mathrm{ml} \cdot \mathrm{min}^{-1} \cdot 1.73 \mathrm{~m}^{-2}$ and albumin excretion rate (AER) $44(20-199) \mu \mathrm{g} /$ min. Light microscopic slides were categorized as: $C$ I) normal or near normal renal structure; C II) changes "typical" of diabetic nephropathology in insulindependent diabetes (ID D M) (glomerular, tubulo-interstitial and arteriolar changes occurring in parallel); C III) "atypical" patterns of injury, with absent or only mild diabetic glomerular changes associated with disproportionately severe renal structural changes including: important tubulo-interstitial with or without arteriolar hyalinosis with or without global glomerular sclerosis. Ten patients $(29.4 \%)$ were classified as C I, 10 as C II (29.4\%) and 14 as C III $(41.2 \%)$; none of these patients had any definable non-diabetic renal disease. GFR, AER and blood pressure were similar in the three groups, while $\mathrm{HbA}_{1 \mathrm{c}}$ was higher in $\mathrm{C} \mathrm{II}$ and $\mathrm{C} \mathrm{III} \mathrm{than} \mathrm{in} \mathrm{C} \mathrm{I} \mathrm{pa-}$ tients. D iabetic retinopathy was present in all C II patients (background in $50 \%$ and proliferative in $50 \%$ ). $\mathrm{N}$ one of the patients in $\mathrm{CI}$ and $\mathrm{C} \mathrm{III} \mathrm{had} \mathrm{proliferative}$ retinopathy, while background retinopathy was observed in $50 \%$ of $\mathrm{CI}$ and $57 \%$ of C III patients. In summary, microalbuminuric NIDDM patients are structurally heterogeneous with less than one third having "typical" diabetic nephropathology. The presence of both "typical" and "atypical" patterns of renal pathology was associated with worse metabolic control, suggesting that hyperglycaemia may cause different patterns of renal injury in older NIDDM compared to younger IDDM patients. [D iabetologia (1996) 39: 1569-1576]

Keywords NIDDM, renal structure, microalbuminuria, glomerular filtration rate.
Diabetic nephropathy is the single most frequent cause of end-stage renal disease in western countries, and the proportion of uraemic patients who are diabetic has been increasing in recent years $[1,2]$. The $U$ nited States $R$ enal $D$ ata System does not yet separate insulin-dependent (IDDM) from non-insulin-

Corresponding author: D r. P. Fioretto, D epartment of I nternal M edicine, V ia G iustiniani 2, I-35128 Padova, I taly

A bbreviations: IDDM, Insulin-dependent diabetes mellitus; NIDDM, non-insulin-dependent diabetes mellitus; DN, diabetic nephropathy; GFR, glomerular filtration rate; $A E R$, albumin excretion rate; PA S, periodic acid-Schiff. dependent (NIDDM) diabetes mellitus. The European Dialysis and Transplant A ssociation R egistry reported that $35 \%$ of diabetic patients requiring renal replacement therapy have NIDDM [2]; however, lack of precision in diabetes classification, originating from insulin-treated (non-insulin-dependent) patients, often classified as having IDDM, may have caused an underestimation of the percent of uraemic diabetic patients affected by NID D M [3]. I ndeed, regional surveys have shown a higher proportion of NIDDM patients on renal replacement therapy, both in the $U$ nited States [4] and in Europe $[3,5,6]$. In Italy, when diabetes was classified by a specific 
questionnaire, the proportion of uraemic NIDDM patients rose to $67 \%$ [6]. A Ithough a large proportion of diabetic patients receiving renal replacement therapy have NIDDM , the pathology and natural history of diabetic nephropathy (DN) in NIDDM is still unclear. The clinical manifestations of D N , proteinuria, declining glomerular filtration rate (GFR) and increasing blood pressure, are similar in IDDM and NIDDM [7, 8]; nevertheless, whether these clinical features are consequences of similar underlying renal lesions is unknown. In ID D M, glomerular, arteriolar, tubular and interstitial structural lesions occur largely in parallel, although glomerulopathy is functionally the most important change [9-14]. Q uantitative morphometric studies have demonstrated that the lesion most closely related to the decline in renal function in IDDM is mesangial expansion, especially mesangial matrix accumulation $[13,15]$. A Iso, we have recently reported, in a longitudinal study with sequential renal biopsies performed 5 years apart in IDDM patients, that the only morphometric parameter associated with increasing albuminuria was mesangial fractional volume [14]. The structural changes occurring in the arterioles, tubules and interstitium are usual concomitants, typically in proportion to the degree of glomerulopathy, and become severe only when glomerulopathy is advanced; in fact advanced global glomerular sclerosis, interstitial fibrosis and arteriolopathy in the absence of abvanced glomerulopathy are uncommon in IDDM .

Non-diabetic renal disease is uncommon in patients who have had IDDM for 10 or more years with overt nephropathy (personal observations), while the prevalence of non-diabetic renal lesions has been reported to be high in proteinuric NIDDM patients (approximately $30 \%$ ). Parving et al. [16] reported that 8 of 35 (23\%) NIDD M patients with proteinuria had non-diabetic glomerulopathies which these authors classified as minimal lesion nephropathy, mesangio-proliferative glomerulonephritis and its sequelae. $\mathrm{H}$ eterogeneity in renal lesions has also been reported by $\mathrm{G}$ ambara et al. [17] who found that only 19 of $52(37 \%)$ of proteinuric NIDDM patients had typical changes of DN. A n autopsy study did not confirm these finding [18].

$M$ icroalbuminuria antedates clinical proteinuria in both ID D M [19-21] and NID D M [22, 23]; however, only approximately $20 \%$ of NIDDM patients with microalbuminuria progress to overt nephropathy over a decade of follow-up in contrast to over $80 \%$ of IDDM patients [23]. Indeed microalbuminuria in NIDDM is a better predictor of cardiovascular mortality than uraemia $[22,24,25]$. The low predictive value of microalbuminuria for overt proteinuria in NID D M may in part be explained by the high mortality for cardiovascular disease, which prevents the progression to clinical nephropathy. However, it has also been hypothesized that microalbuminuria in
NIDDM patients may be either consequent to diabetic glomerulopathy, as in ID D M, or reflect generalized endothelial dysfunction $[8,26]$. This latter hypothesis remains speculative, since to date no information is available on renal structure in NID D M patients with microalbuminuria.

The present study investigates renal function and structure in 34 microalbuminuric NIDDM patients in order to describe the renal structural concomitants of this functional disturbance.

\section{Subjects and methods}

Patients. The patients were participating in an ongoing multicenter study of renal structural-functional relationships in NIDDM . Patients were referred to the U niversity of Padova from diabetes centres in the north-east of I taly for research evaluation of renal structure and function, based upon the following criteria.

1. A ge 70 years or less.

2. A ge at diagnosis of NIDD M 40 years or more. Diabetic patients were diagnosed as having NID D M when onset was after age 40 years, when they were treated with diet alone or in association with oral hypoglycaemic agents and/or insulin and when they were not receiving insulin in the first 2 years after diagnosis. Insulin-treated patients with normal body weight had a glucagon test performed to confirm the diagnosis of NIDDM (when C-peptide levels were normal).

3. K nown duration of NIDD M 2 years or more.

4. Serum creatinine $<180 \mu \mathrm{mol} / \mathrm{l}$.

5. A bsence of other obvious renal diseases including serious stone disease, and presence of single kidney.

6 . Secondary causes of hypertension including known renal artery stenosis and endocrinopathy.

7. R equirement for systemic anticoagulation (heparin or coumadin).

O therwise all patients willing to participate were accepted regardless of renal function. In no case were renal biopsies performed for clinically indicated diagnostic purposes.

To date light microscopic slides from 34 microalbuminuric patients have been evaluated and are presented here. Patients were defined as microalbuminuric when AER was $20 \mu \mathrm{g}$ or $\mathrm{more} / \mathrm{min}$ but $200 \mu \mathrm{g}$ or less/min in at least two of three consecutive sterile 24-h urine collections.

These studies were approved by the ethical committee of the U niversity of Padova. Patients gave written informed consent before each study. The patients were admitted to the D epartment of Internal Medicine at the U niversity of Padova $\mathrm{H}$ ospital where percutaneous renal biopsy and renal functional studies were performed. In patients on antihypertensive treatment, the therapy was withdrawn 3-5 days before and during admission; after the studies were completed, patients were returned to their previous therapy. During admission patients underwent at least three 24-h urine collections for measurements of $A E R$ after urine cultures were determined to be sterile. If bacterial growth was present, treatment was initiated and urine collections were repeated for determination of $A E R$ on sterile urine samples. M icroscopic examination of the urinary sediment was performed. G lomerular filtration rate was determined by the plasma clearance of Cr-EDTA, as described in detail elsewhere [27]. Blood pressure was measured at least 10 times with the patient in the supine position. B ody mass in$\operatorname{dex}\left(\mathrm{B}\right.$ M I) was calculated as weight $(\mathrm{kg}) /$ height $\left(\mathrm{m}^{2}\right)$. Patients 
were defined hypertensive when the blood pressure values exceeded 140/85 mm H g [28], or when on antihypertensive therapy regardless of $\mathrm{BP}$ levels. $\mathrm{HbA}_{1 \mathrm{c}}$ was measured to assess metabolic control. A II patients had funduscopy performed through dilated pupils in the Department of O phthalmology of the $U$ niversity of Padova and, when required, fluoroangiographic studies. Patients were classified as follows: 1) absence of diabetic retinopathy; 2 ) background diabetic retinopathy; 3 ) proliferative diabetic retinopathy.

Normal control subjects. K idney biopsies were obtained from 36 (17 male /19 female) kidney donors at the time of renal transplantation at the U niversity of M innesota. Thirty-three of these donors were living related donors and three were cadavers; these control subjects were matched for age with the diabetic patients (age: $55.7 \pm 7$ years, range: 45.1-69).

A nalytical procedures. $\mathrm{HbA}_{1 \mathrm{c}}$ values were measured by highperformance liquid chromatography (DIAMAT A nalyzer, BIO-R A D, Calif., USA ). A ER was measured by radioimmunoassay. ${ }^{51} \mathrm{Cr}$ radioactivity was measured in duplicate $1-\mathrm{ml}$ aliquots of plasma in a gamma counter (C obra-5002 CPM , Camberra Packard, M ilan, I taly) with the energy window set to 240 $400 \mathrm{~K} \mathrm{eV}$ [27].

Renal structure. K idney biopsies were performed under ultrasound guidance by experienced investigators. Safety requirements included normal blood pressure levels $(\leq 140 / 85 \mathrm{~mm}$ $\mathrm{Hg}$ ) at the time of the biopsy as well as normal coagulation studies and platelet counts. A spirin or other antiplatelet agents were withdrawn 2 weeks before the biopsy. A fter kidney biopsy, tissue was immediately examined under a dissecting microscope to ensure adequate numbers of glomeruli.

Light microscopy. M ost of the core was placed in Zenker's fixative, embedded in paraffin and processed for light microscopy [29]. Light microscopy sections (2- $\mu \mathrm{m}$ thick) were stained with haematoxylin and eosin and periodic acid Schiff (PA S). PA S sections from all patients and normal control subjects were concomitantly and blindly evaluated by two observers, in order to develop a qualitative overview of the patterns of injury. The two observers evaluated the light microscopy slides simultaneously, and therefore an agreement on the categorization was discussed and made at the time of the reading. B ased on the resultant overview of the biopsy material the following classification was developed:

Category C I): N ormal or near normal renal structure. These patients had biopsies which were normal or showed very mild mesangial expansion, tubulo-interstitial changes or arteriolar hyalinosis in any combination (Fig. 1A ).

Category C II): Typical diabetic nephropathology. These patients had established diabetic lesions with balanced severity of glomerular, tubulo-interstitial and arteriolar changes. This picture is typical of that seen in IDDM patients with obvious light microscopic DN changes (Fig. 1B).

The severity of lesions in the different compartments, as well as the possible heterogeneity among different glomerular profiles, was evaluated as described elsewhere [13]. Q uantitative morphometric measures of mesangial $(r=0.87, p<$ $0.0001)$ [13] and interstitial expansion $(r=0.90, p<0.0001)$ [30] are closely correlated with the semiquantitative light microscopic analysis. O ur previous studies have shown highly significant correlations between glomerular lesions, interstitial expansion, arteriolar hyalinosis and global glomerular sclerosis $[11,13,31]$.
Category C III): A typical patterns of renal injury. These patients had absent or only mild glomerular diabetic changes with disproportionately severe renal structural lesions including:

(a) Tubular atrophy, tubular basement membrane thickening and reduplication and interstitial fibrosis (tubulo-interstitial lesions) (Fig. 1C).

(b) A dvanced glomerular arteriolar hyalinosis commonly associated with atherosclerosis of larger vessels (Fig. 1D).

(c) G lobal glomerular sclerosis ( $>25 \%$ ) in the presence of absent or mild mesangial expansion (index of mesangial expansion $\leq 0.5$ according to our score system [13]) (Fig.1E ).

These patterns were present in any possible combination. Considering the complexity of the patterns of injury and the limited number of patients, we pooled these three groups $(a, b, c)$ into one single category (C III).

It should be noted that patients in categories III and II could have similar levels of diabetic glomerulopathy, expressed as index of mesangial expansion, but those in C III had disproportionately severe tubulointerstitial, vascular or glomerulosclerotic lesions.

I mmunofluorescent microscopy. O ne 2-3 mm cortical core was snap frozen for immunofluorescence studies. The tissue was blindly examined using rabbit or goat antisera specifically reactive to human IgA , IgG , IgM , fibrinogen, C3, C4, C1q.

E lectron microscopy. Three 1-mm cortical cores were placed in $2.5 \%$ glutaraldehyde in Millonig's buffer and processed for electron microscopy [29]. U Itrathin sections were obtained on an LKB ultramicrotome (LKB, Bromma, Sweden) and observed on a $\mathrm{H}$ itachi $\mathrm{H} / 600$ elecron microscope (H itachi, Tokyo, Japan). Three glomeruli per biopsy were examined and pictures taken at final magnifications of $3900 \times$ and $12000 \times$, as previously described [32]. Electron microscopic morphometric analysis is in progress. Photomicrographs obtained at 12 $000 \times$ were analysed for diagnostic purposes.

None of the patients in the three groups described above had light immunofluorescent or electron microscopy findings of any definable renal disease other than typical diabetic nephropathy or the patterns described above.

\section{Statistical analysis}

$D$ ata are expressed as mean $\pm 1 S D$. Values for A E R, not normally distributed, were logarithmically transformed before analysis and are expressed as median and range. Comparisons among the diabetic groups first used a one-way analysis of variance (A N OVA) and then unpaired Student's t-test for parameters shown to be different by A NOVA. Values of $p<0.05$ were considered significant.

\section{Results}

Clinical features of patients. Twenty-six of the 34 patients (all Caucasian) were males. A ge was $58.5 \pm$ 7.3 years ( mean $\pm 1 S D$ ) and known NID D M duration was $10.8 \pm 6.3$ years. Body mass index (BMI) was $28.9 \pm 3.9 \mathrm{~kg} / \mathrm{m}^{2}$ (normal values in a group of agematched normal control subjects: $24 \pm 2$ ) and $\mathrm{H} \mathrm{bA}_{1 \mathrm{c}}$ was $8.5 \pm 1.6 \%$ (normal range: $4.1-6.1 \%$ ). GFR was $101 \pm 27 \mathrm{ml} \cdot \mathrm{min}^{-1} \cdot 1.73 \mathrm{~m}^{-2}$ (normal range in a 

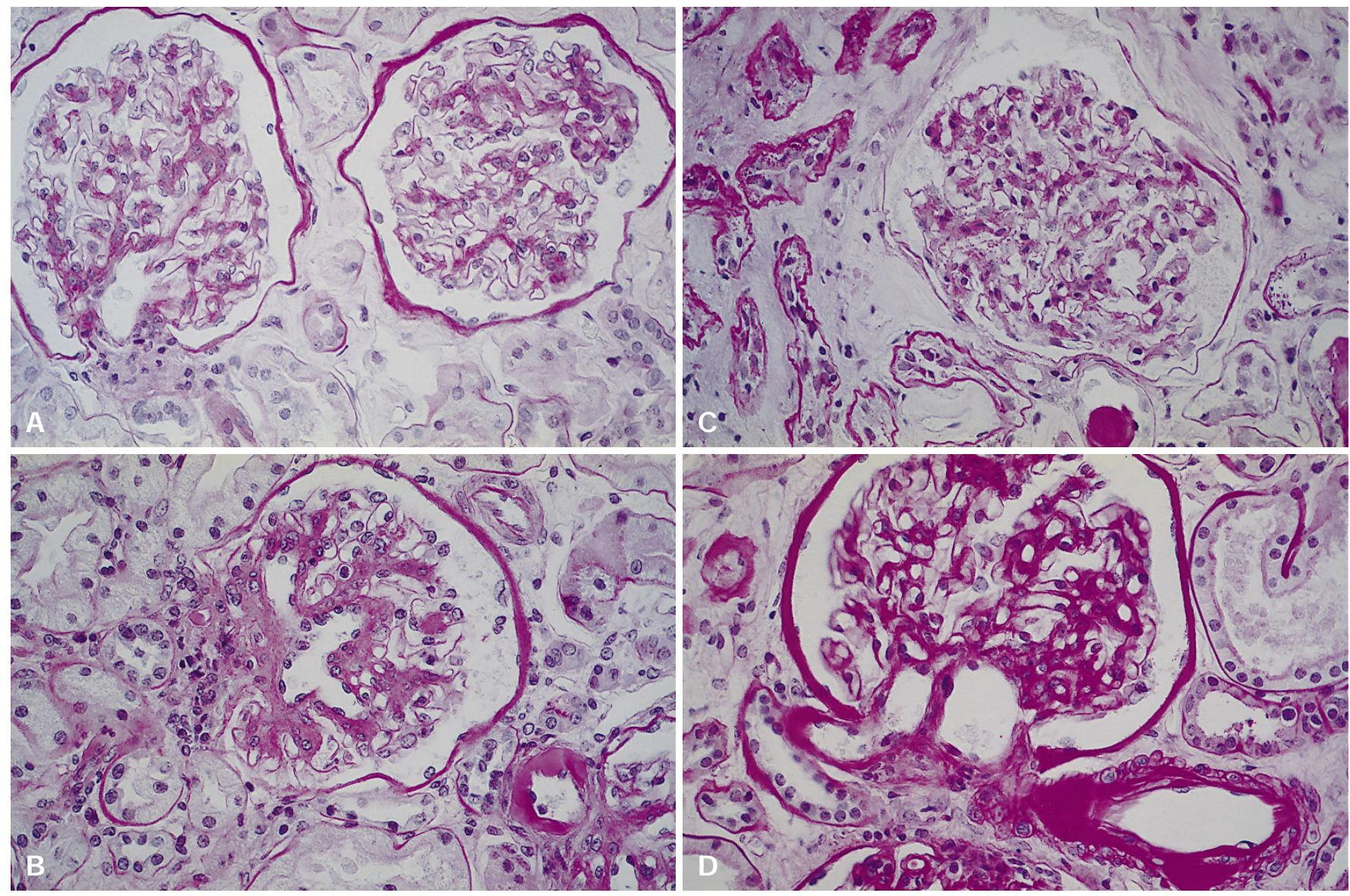

Fig. 1. A G lomeruli from a patient in category C I. G lomerular structure is near normal with minimal mesangial expansion (PA S). B G lomerulus from a patient in category C II, with well-established diabetic nephropathology. Diffuse mesangial expansion, advanced arteriolar hyalinosis and mild interstitial fibrosis are present (PA S). C Glomerulus from a patient in category C III (a), with near normal glomerular structure and tubular basement membrane thickening, tubular atrophy and severe interstitial fibrosis (PA S). D G lomerulus from a patient in category C III (b), with mild mesangial expansion and severe arteriolar hyalinosis, affecting both afferent and efferent glomerular arterioles (PA S). E Glomeruli from a patient in category C III (c). G lomerular structure is near normal in one glomerulus, while the adjacent shows global glomerular sclerosis (PA S)

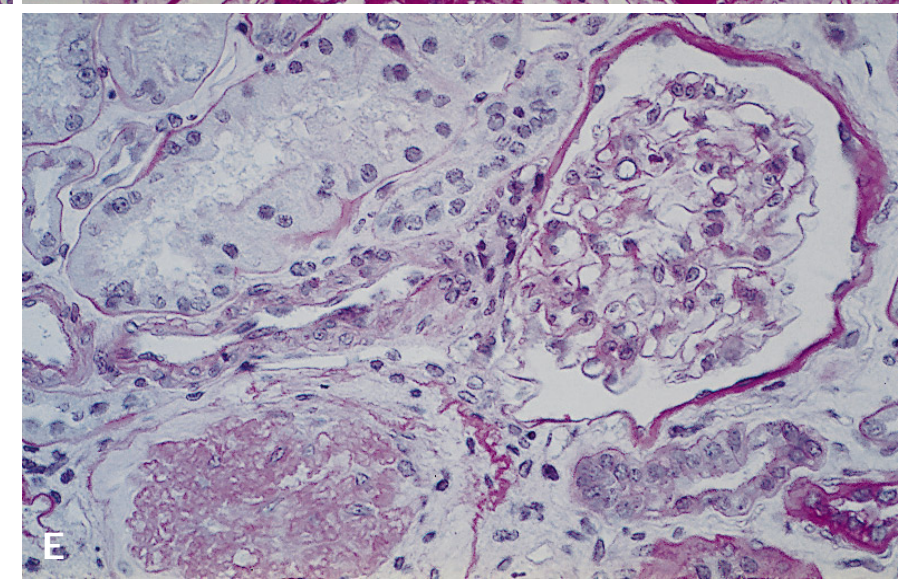

group of 19 age and sex-matched normal control subjects: 85-135) and A E R was 44 (20-199) $\mu \mathrm{g} / \mathrm{min}$ (median, range) (normal values: 5 [0-14]).

A II but 6 patients were receiving antihypertensive therapy, and the majority of them were on A CE inhibition. O verall, only 3 patients were normotensive, according to the criteria described above.

$B$ ased on the light microscopic findings 10 patients ( 5 male/5 female) were allocated to category I $(29.4 \%), 10$ patients ( 9 male/ 1 female) to category II $(29.4 \%)$ and 14 ( 10 male/2 female) to category III $(41.2 \%)$. Important tubulo-interstitial changes were observed in all but 1 patient, who had very severe

arteriolar hyalinosis lesions, in category $\mathrm{III}$; these tubulo-interstitial lesions were often associated with arteriolar changes and in some $(n=3)$ patients to severe (> $25 \%$ ) global glomerular sclerosis.

The frequency of global glomerular sclerosis was 0 (0-20) (median, range) in $\mathrm{Cl}, 0$ (0-36) in $\mathrm{CII}$ and 4 (0-46) in CIII.

The clinical features of the patients as divided into the three structural groups are summarized in Tables 1 and 2.

$\mathrm{Cl}$ patients tended to be younger than patients in groups $\mathrm{CII}$ and $\mathrm{CIII}$, although the difference was not significant by A NOVA ( $p=0.13) ; 50 \%$ of patients in 
Table 1. Clinical features of patients divided into three renal structural categories

\begin{tabular}{lcclcll}
\hline Category & male/female & $\%$ & $\begin{array}{l}\text { A ge } \\
\text { (years) }\end{array}$ & $\begin{array}{l}\text { K nown N ID D M duration } \\
\text { (years) }\end{array}$ & $\begin{array}{l}\mathrm{B} \mathrm{M} \mathrm{I} \\
\left(\mathrm{kg} / \mathrm{m}^{2}\right)\end{array}$ & $\begin{array}{l}\mathrm{HbA}_{1 c} \\
(\%)\end{array}$ \\
\hline C I & $5 / 5$ & 23.4 & $54 \pm 9$ & $8 \pm 3$ & $31 \pm 4^{\mathrm{b}}$ & $7.5 \pm 0.8$ \\
C II & $9 / 1$ & 29.4 & $60 \pm 6$ & $14 \pm 6^{\mathrm{a}}$ & $26 \pm 4$ & $9.6 \pm 1.8^{\mathrm{d}}$ \\
C III & $12 / 2$ & 41.2 & $61 \pm 6$ & $10 \pm 8$ & $30 \pm 3^{\mathrm{b}}$ & $8.5 \pm 1.3^{\mathrm{c}}$ \\
p values & & & & & &
\end{tabular}

$\mathrm{D}$ ata are mean $\pm \mathrm{SD}$

${ }^{a} p<0.05$ vs $C$ I and C III; ${ }^{b} p<0.03$ vs C II; $p<0.05$ vs C I; ${ }^{d} p<0.005$ vs $C$ I

Table 2. R enal function and blood pressure of patients divided into three renal structural categories

\begin{tabular}{lllll}
\hline Category & $\begin{array}{l}\text { A ER } \\
(\mu \mathrm{g} / \mathrm{min})\end{array}$ & $\begin{array}{l}\mathrm{GFR} \\
\left(\mathrm{ml} \cdot \mathrm{min}^{-1} \cdot 1.73 \mathrm{~m}^{-2}\right)\end{array}$ & B lood pressure & \\
\cline { 3 - 5 } & & $111 \pm 20$ & $142 \pm 19$ & Diastolic $(\mathrm{mmH} \mathrm{g})$ \\
\hline C I & $45(20-198)$ & $91 \pm 36$ & $154 \pm 13$ & $91 \pm 10$ \\
C II & $50(22-190)$ & $101 \pm 21$ & $155 \pm 16$ & $92 \pm 7$ \\
C III & $39(20-198)$ & & $90 \pm 10$ \\
\hline
\end{tabular}

$\mathrm{D}$ ata are mean \pm SD (AER is median and range) NS for all comparisons

Table 3. Diabetic retinopathy in relation to patterns of renal injury

\begin{tabular}{llll}
\hline Category & \multicolumn{3}{l}{ Diabetic retinopathy } \\
\cline { 2 - 4 } & A bsent & Background & Proliferative \\
\hline C I & 5 & 5 & 0 \\
C III & 0 & 5 & 5 \\
C III & 6 & 8 & 0 \\
\hline
\end{tabular}

$\mathrm{Cl}$ were females, while in groups $\mathrm{CII}$ and $\mathrm{CIII}$ there was a clear preponderance of males (Table 1 ). K nown duration of NIDDM tended to be different among groups ( $A$ NOVA, $p=0.08$ ), with group CII patients having the longest duration (t-tests, $\mathrm{p}<0.05$ vs $\mathrm{Cl}$ and $\mathrm{CIII}) . \mathrm{HbA}_{1 \mathrm{c}}$ levels were significantly different among groups ( $A$ N OVA , $p<0.01$ ); subsequent analysis showed that $\mathrm{CII}$ and $\mathrm{CIII}$ patients had higher $\mathrm{H} \mathrm{bA}_{1 \mathrm{c}}$ values than $\mathrm{Cl}$ patients ( $\mathrm{t}$-tests, $\mathrm{p}<0.005$ and $p<0.05$, respectively). B M I was also different among groups ( $A$ NOVA , $p<0.02$ ); B M I was only mildly increased in CII patients (range: 18.1-31.5) and was significantly higher in $\mathrm{CI}$ (range: 27.7-40.1) and CIII patients (24.5-35.1) compared to CII (t-tests, $p<0.05$ for both). AER levels were superimposable in the three groups (Table 2). G FR was not different in the three groups of patients; however, 5 of the 10 patients in CII had GFR values under $85 \mathrm{ml} \cdot \mathrm{min}^{-1} \cdot 1.73 \mathrm{~m}^{-2}$ compared to 1 of 10 in $\mathrm{Cl}$ and 2 of 14 in CIII. Systolic and diastolic blood pressure values were similar in the three groups; two of the 3 normotensive patients were in group $\mathrm{Cl}$ and one in group $\mathrm{CIII}$. Seven of 10 patients in group $\mathrm{Cl}, 10$ of 10 in group $\mathrm{Cll}$ and 11 of 14 in group CIII were receiving antihypertensive therapy.

R esults of the funduscopic or fluoroangiographic evaluations are given in Table 3 . In several patients varying degrees of hypertensive retinopathy were present with or without diabetic retinopathy.
Normal control subjects. B ased on the scores for interstitial fibrosis, 3 of $36(8 \%)$ subjects had important tubulo-interstitial changes. Several normal control subjects had mild arteriolar hyalinosis lesions; 6 $(16 \%)$ had more advanced arteriolar lesion scores, comparable to those observed in patients in categories $\mathrm{II}$ and III (scores $\geq 1.0$ according to our previously described scoring system [13]). H owever, none of the control subjects had arteriolar hyalinosis lesions of comparable severity to those observed in the patients categorized in group III because of vascular changes.

\section{Discussion}

In IDDM patients with long disease duration ( $\geq 10$ years) and overt nephropathy, non-diabetic renal disease is rare ( $M$ auer $M$, unpublished data). Thus, in the vast majority of long-term IDDM patients, the loss of kidney function is related to a welldefined pattern of diabetic nephropathology, including glomerular basement membrane and tubular basement membrane thickening and mesangial expansion, especially matrix accumulation, but also arteriolar hyalinosis affecting both afferent and efferent glomerular arterioles [9-15]. Interstitial fibrosis is frequently present, especially in patients with advanced glomerulopathy and typically in areas with global glomerular sclerosis and tubular atrophy [11, 13]. This pattern of renal lesions is quite monotonous and predictable in ID DM patients with clinical nephropathy.

Three studies have reported that non-diabetic renal disease is quite frequent in NIDDM patients with overt nephropathy. Parving et al. [16] found that 1 of 4 of such patients had renal diseases other than diabetes; Gambara et al. [17] confirmed these 
data reporting that only 1 of 3 of NIDDM patients with overt nephropathy had typical patterns of $D N$. $K$ han et al. [33] recently observed the presence of non-diabetic renal disease in $42 \%$ of 153 NID D M patients with overt nephropathy; the occurrence of nondiabetic renal disease was much lower $(12 \%)$ in the series of 33 proteinuric patients studied by OIsen and M ogensen [34]. In all these studies, however, patients were referred to the nephrologist and kidney biopsies were not performed on the basis of research protocols, but for clinical indications. Thus, these studies do not describe the usual NIDDM patients with nephropathy, but those with an unusual clinical course; also the different results may reflect differences in the criteria for kidney biopsy. A large autopsy study on NIDDM patients did not confirm a high incidence of non-diabetic renal diseases [18]. Thus, the available data on renal structure in N I D D M patients with proteinuria are still inconclusive.

Microalbuminuria in NIDDM has been shown to predict mortality, mainly cardiovascular [22, 24, 25] and, in approximately $20 \%$ of patients, the development of overt proteinuria [23]. However, whether the raised urinary albumin excretion is an expression of underlying diabetic renal lesions is still unknown. Only one study to date evaluated renal structure in microalbuminuric NID D M patients [35]; surprisingly these authors, who reported diagnostic heterogeneity in proteinuric NIDDM patients [17], found that all 16 microalbuminuric NID D M patients had classic lesions of diabetic glomerulopathy.

Since 1992 we have been performing kidney biopsies on the basis of a research protocol rather than clinical indications. The present paper summarizes the preliminary analysis in the microalbuminuric patients studied to date.

The initial reading of the light microscopy tissue of these NIDDM patients made apparent the inadequacy of current descriptive formulations, largely based on observations of research biopsies in ID DM (of which the authors have reviewed several hundreds). Virtually all IDDM patients with at least 10 years of diabetes and overt nephropathy have obvious diabetic glomerulopathy. D iabetic glomerulopathy, although less severe, is usually quite advanced in microalbuminuric IDD M patients. We recently reported that all IDDM patients with A ER over $30 \mu \mathrm{g} /$ min had electron microscopic morphometric measures of diabetic glomerulopathy above the normal range [32]. Since electron microscopic morphometric analysis has not been completed in these patients, it is currently impossible to make any precise comparison between diabetic glomerulopathy in IDDM and NIDDM microalbuminuric patients. Nevertheless, many NIDDM patients with microalbuminuria did not have glomerulopathy, or they had very mild mesangial expansion by light microscopy. Thus, $70 \%$ of the microalbuminuric NIDDM patients had normal or near normal glomerular structure by light microscopy, with or without tubulo-interstitial and arteriolar changes. The remaining 30\% had renal changes typical of D N in ID D M, with glomerular, tubulo-interstitial and vascular lesions occurring in parallel.

Thus, we developed a new classification system which included three major groups. Category I was defined as normal or near-normal renal structure, category II as "typical" patterns of renal injury (similar to the changes in IDDM ). Category III was defined as "atypical" patterns of renal injury, including severe tubulo-interstitial and/or arteriolar hyalinosis and/or global glomerular sclerosis lesions in the presence of absent or mild glomerular changes.

Thus, despite comparable renal function, NID D M patients with microalbuminuria are structurally heterogeneous: only $29 \%$ had "typical" D N, $29 \%$ had near normal renal structure and $42 \%$ severe tubulointerstitial and/or vascular lesions disproportionate to the mild glomerular involvement. In this series of patients we did not find cases of any definable non-diabetic renal disease. The difference between our findings and those in previous reports in proteinuric NIDDM patients (see above) may be explained by the study design, in that patients in the present study had kidney biopsies performed on the basis of a research protocol as opposed to clinical indication for atypical course.

The "atypical" patterns of renal injury observed in many of our patients are probably related to hyperglycaemia, since $\mathrm{H} \mathrm{bA}_{1 \mathrm{c}}$ levels were higher both in patients with "typical" and with "atypical" patterns of lesions compared to patients without lesions. Thus, hyperglycaemia may cause different patterns of renal injury in older NIDDM compared to younger IDDM patients. The tubulo-interstitial and vascular changes could also be related to aging and systemic hypertension. H owever, hypertension was present in almost all patients (except for 3 ) in all 3 structural categories, and "per se" cannot account for the different lesions observed in category III. Further, mean age was similar in category II and III patients, despite the different patterns of renal injury in the two groups. A Iso, we examined a large number of agematched normal control subjects and found that severe lesions, as observed in NIDDM patients, were uncommon in the non-diabetic subjects. Nevertheless, aging and blood pressure may have varying impact in different patients, and therefore may contribute, in presence of other factors, to renal injury in this subset of patients.

The reasons why the kidney may react differently to hyperglycaemia in different patients with NID D M are not clear. It can be hypothesized that the heterogeneity in renal structure might reflect the heterogeneous nature of NIDDM "per se". Patients with "typical" D N lesions had the longest known diabetes duration, worse metabolic control and they all had 
diabetic retinopathy; interestingly their BMI only slightly exceeded normal values, as opposed to clearly increased B M I values in categories I and III .

The nature of this interrelationship of diabetic milieu and renal structural changes remains enigmatic; however, these relationships also extend to diabetic retinopathy. Diabetic retinopathy was present in all C II patients, background in $50 \%$ and proliferative in $50 \%$. None of the patients in C I and C III had proliferative retinopathy, while background diabetic retinopathy was observed in $50 \%$ of $\mathrm{CI}$ and $57 \%$ of $\mathrm{C}$ III patients. Thus, all C II patients had diabetic retinopathy and all patients with proliferative retinopathy had "typical" D N.

A high proportion of microalbuminuric NIDDM patients $(29 \%)$ had normal or near-normal renal structure. They tended to be younger and had shorter diabetes duration and better metabolic control than patients with renal lesions (categories II and III). A Ithough we do not have an explanation for the abnormal AER in these patients, it is possible that microalbuminuria in this subset is a clinical manifestation of generalized endothelial dysfunction rather than of renal damage "per se". Parving et al. [16] observed what they termed "minimal lesion" nephropathy in 4 of 36 NIDDM patients with clinical proteinuria. It is possible that the patients diagnosed as having "minimal lesion" nephropathy in thislatter study are similar to our category I patients, however this will require longitudinal studies to be addressed. Suffice it to say here that a substantial proportion of NIDD M patients with microalbuminuria or proteinuria may have increased glomerular capillary wall permeability to protein for reasons not currently understood.

In summary, in this unselected series of 34 cases biopsied for research reasons, NIDDM patients with microalbuminuria do not have non-diabetic renal diseases; however they may have different patterns of renal injury compared to IDDM patients. More "typical" diabetic nephropathy patterns are seen among microalbuminuric NIDD M patients with proliferative retinopathy and normal BMI, while "atypical" patterns of renal injury are more common among those with increased BMI and background or no retinopathy. Finally, a subset of microalbuminuric NIDDM patients have near-normal renal structure by light microscopy; in these patients the increased renal permeability to protein might be expression of generalized endothelial dysfunction.

L ong-term longitudinal studies are needed to determine the course of renal function in these patients with different patterns of renal injury.

A cknowledgements. This work was supported by grants from the Italian National Research Council (PF 40\# 9300428, 9400464), the Italian A ssociation LIONS for Diabetes and B ayer Company, Milan, Italy. Dr. P. Fioretto is the recipient of the A lbert R enold Fellowship award from the EA SD. The method for the mathematical analysis of GFR was supplied by the LA D SE B-CNR, Padova (D r. K. Thomaseth). We thank $M$ isses B. M azzucato, I. B arzon, L. Trivellato and L. Samadello for expert technical help. We are indebted to all the patients who participated in these studies and to the nursing staff of the D epartment of I nternal M edicine of the U niversity of Padova H ospitals.

\section{References}

1. The 1993 U SR D S A nnual D ata R eport. Incidence and causes of treated ESRD (1993). A m J Kidney D is 23[Suppl 2]:38-45

2. R aine A EG (1993) E pidemiology, development and treatment of end-stage renal failure in type 2 (non-insulin-dependent) diabetic patients in Europe. Diabetologia 36: 1099-1104

3. Cordonnier DJ , Z mirou D, B enhamou PY, H alimi S, L edoux F, G uiserix J (1993). E pidemiology, development and treatment of end-stage renal failure in type 2 (non-insulin-dependent) diabetes mellitus. The case of mainland France and of overseas French territories. D iabetologia 36: 1109-1112

4. Stephen SG W, G illaspry JA, Clyne D, M ejia A, Pollok V E (1990) R acial differences in the incidence of end stage renal disease in type 1 and type 2 diabetes mellitus. A m J K idney $D$ is 15: $562-567$

5. R itz E, N owack R, Fliser D, et al. (1991) Type II diabetes mellitus: is the renal risk adequately appreciated? Nephrol D ial Transplant 6: 679-682

6. Catalano C, Postorino M, K elly PJ (1990) D iabetes mellitus and renal replacement therapy in Italy: prevalence, main characteristic and complications. Nephrol Dial Transplant 5: 788-796

7. Mogensen CE, Schmitz A, Christiensen CK (1988) Comparative renal pathophysyology relevant to IDDM and NIDDM patients. D iabet M etab R ev 4: 453-483

8. Schmitz A (1995) Nephropathy in non-insulin dependent diabetes mellitus and perspectives for intervention. Diab N utr M etab 7: 135-148

9. M auer SM, Steffes M W, B rown DM (1981) The kidney in diabetes. $A$ m J M ed 70: 603-612

10. Fioretto P, Mogensen CE, Mauer SM (1994) Diabetic nephropathy. In: Holliday MA, B arratt TM, A vner ED (eds) Pediatric nephrology. Williams and Wilkins, New York, pp 576-585

11. L ane PH, Steffes M W, Fioretto P, M auer SM (1993) R enal interstitial expansion in insulin-dependent diabetes mellitus. K idney Int 43: 661-667

12. G ellman DD, Pirani CL, Soothill JF, Muehrcke R C, M aduros W, Kark R M (1959) Structure and function in diabetic nephropathy: the importance of diffuse glomerulosclerosis. D iabetes 8: 251

13. M auer SM, Steffes M W, Ellis E N, Sutherland DE R, B rown D M , G oetz FC (1984) Structural functional relationships in diabetic nephropathy. J Clin Invest 74: 1143-1155

14. Fioretto P, Steffes M W, Sutherland DE R, M auer M (1995) Sequential renal biopsies in IDD M patients: structural factors associated with clinical progression. Kidney Int 48: 1929- 1935

15. Steffes MW, Bilous RW, Sutherland DER, Mauer SM (1992) Cell and matrix components in the glomerular mesangium in type I diabetes. D iabetes 41: 679-684

16. Parving $\mathrm{H}-\mathrm{H}$, G all M-A, Skøtt $P$ et al. (1992) Prevalence and causes of albuminuria in non-insulin-dependent diabetic patients. Kidney Int 41: 758-762 
17. G ambara V, M ecca G, R emuzzi G, B ertani T (1993) H eterogeneous nature of renal lesions in type II diabetes. JA SN 3: $1458-1466$

18. Waldherr R, Ilkenhans C, Ritz E (1992) How frequent is glomerulonephritis in diabetes mellitus type II? Clin N ephro 37: 271-273

19. Viberti G C, H ill R D, Jarrett R J, A rgyropoulos A, M ahmud $U$, K een H (1982) M icroalbuminuria as a predictor of clinical nephropathy in insulin-dependent diabetes mellitus. L ancet I:1430-1432

20. Parving $\mathrm{H}-\mathrm{H}, \mathrm{O}$ xenbø\| B, Svensen PA A , Christiansen J S, A ndersen A R (1982) E arly detection of patients at risk of developing diabetic nephropathy: a longitudinal study of urinary albumin excretion. A cta Endocrinol Copenh 100: 550-552

21. M ogensen CE , Christensen CK (1986) Predicting diabetic nephropathy in insulin-dependent diabetic patients. $\mathrm{N}$ Engl J Med 331: 89-93

22. M ogensen CE (1984) M icroalbuminuria predicts clinical proteinuria and early mortality in maturity-onset diabetes. N Engl J M ed 310: 356-360

23. M ogensen CE (1987) M icroalbuminuria as a predictor of clinical diabetic nephropathy. K idney Int 31: 673-689

24. Schmitz A , Vaeth M (1988) M icroalbuminuria: a major risk factor in type 2 diabetes. A 10 year follow-up study of 503 patients. D iabet Med 5: 126-134

25. Jarrett RJ, V iberti G C, A rgyropoulos A, H ill R D, M ahmud U, M urrells TJ (1984) M icroalbuminuria predicts mortality in non-insulin-dependent diabetes. D iab M ed 1: 17-19

26. Stehouwer CDA, Nauta JJP, Zeldenrust GC, Hackeng WH L, D onker A J M, den Ottolander G J H (1992) U rinary albumin excretion, cardiovascular disease, and endothelial dysfunction in non-insulin dependent diabetes mellitus. L ancet 340: 319-323
27. Sambataro M , Thomaseth K, Pacini G et al. (1996) Plasma clearance of $51 \mathrm{Cr}$-EDTA provides a precise and convenient technique for measurement of glomerular filtration rate in diabetic humans. JA SN 7: 1-10

28. The Fifth R eport of the Joint $\mathrm{N}$ ational Committee on $\mathrm{De}$ tection, E valuation, and Treatment of $\mathrm{H}$ igh $\mathrm{B}$ lood Pressure (1993) A rch Int M ed 153: 154-183

29. Ellis E N, B asgen J M, M auer SM, Steffes M W (1986) Kidney biopsy technique an evaluation. In: Clarke $W L$, L arner J, Pohl SL (eds) M ethods in diabetes research, volume II clinical methods. John Wiley \& Sons, New York, pp 633647

30. Fioretto $P$, Steffes M W, M ihatsch MJ, Strøm EH, Sutherland DER, M auer M (1995) Cyclosporine associated lesions in the native kidneys of diabetic pancreas transplant recipients. K idney Int 48: 489-495

31. Harris RH, Steffes MW, Sutherland DER, Mauer SM (1991) G lobal glomerular sclerosis and arteriolar hyalinosis in insulin-dependent diabetes. Kidney Int 40: 107-114

32. Fioretto P, Steffes M W, M auer M (1994) G lomerular structure in non proteinuric IDDM patients with various levels of albuminuria. D iabetes 43: 1358-1364

33. K ahn S, Seghal V, A ppel G B, D 'A gati V (1995) Correlates of diabetic and non-diabetic renal disease in NIDDM. JA SN 6: 451 (A bstract)

34. OIsen S, M ogensen CE (1995) Non-diabetic renal disease in NIDDM proteinuric patients may be rare in biopsies from clinical practice. JA SN 6: 454 (A bstract)

35. R uggenenti P, Mosconi L, Bianchi L et al. (1994) Longterm treatment with either enalapril or nitrendipine stabilizes albuminuria and increases glomerular filtration rate in non-insulin-dependent diabetic patients. A m J Kidney D is 24: 753-761 